\title{
The effect of sacroiliac joint manual therapy on heart rate variability in women with primary dysmenorrhea
}

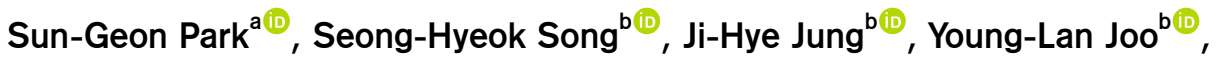 \\ You-Jin Yang ${ }^{c(1)}$, Seungwon Lee ${ }^{\mathrm{d}, e(1)}$

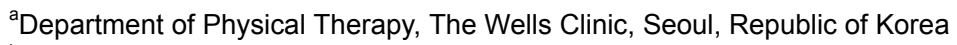 \\ ${ }^{b}$ Department of Physical Therapy, The Graduate School, Sahmyook University, Seoul, Republic of Korea \\ ${ }^{\mathrm{c} D e p a r t m e n t}$ of Physical Therapy, Gangwon-do Wonju Medical Center, Wonju, Republic of Korea \\ ${ }^{d}$ Department of Physical Therapy, College of Health Science and Social Welfare, Sahmyook University, Seoul, Republic of Korea \\ eInstitute of SMART Rehabilitation, Sahmyook University, Seoul, Republic of Korea
}

Objective: Disorder of the autonomic nervous system is considered to be the cause of primary dysmenorrhea. The spine has a close relationship with the autonomic nervous system, and the sacrum is mechanically and neurologically connected to the uterus through ligaments. Therefore, this study was conducted to check the effect on the autonomic nervous system through measurement of heart rate variability by applying manual therapy to the sacroiliac joints of subjects with primary dysmenorrhea and to suggest an effective treatment method for dysmenorrhea.

Design: Randomized controlled trial.

Methods: Thirty females with dysmenorrhea were assigned to either the manual therapy group and sham treatment group according to the random treatment method. The manual therapy was applied to the sacroiliac joints, and the sham treatment was only treated with the hands placed in the same position of the intervention. Heart rate variability and the Visual Analogue Scale (VAS) were measured on the day when menstruation began \pm 2 . Interventions were performed between the groups, followed by a 5-minute break and then re-measurements were made.

Results: There were significant differences in autonomic balance and VAS scores in the manual therapy group before and after the intervention between groups $(p<0.05)$. In the sham treatment group, there were significant differences in low frequency, autonomic balance, and VAS scores $(p<0.05)$. There were significant differences in autonomic balance between groups $(p<0.05)$.

Conclusions: In females with primary dysmenorrhea, manual therapy applied to the sacroiliac joint was found to be effective for a short time on autonomic activity.

Key Words: Dysmenorrhea, Heart rate variability, Musculoskeletal manipulations, Sacroiliac joint

\section{Introduction}

Pain in the lower abdomen, which occurs when the cervix convulsion continues for 6 to 72 hours with the onset of menstrual flow, is called dysmenorrhea [1,2]. During this period, back and thigh pain, fatigue, diarrhea, constipation, and headache may be accompanied. This leads to absenteeism from work or school, interruptions in daily life, and in- creased social costs [3].

Dysmenorrhea is mainly classified into primary and secondary dysmenorrhea. Primary dysmenorrhea has no pathological findings. Most females experience this, and it occurs most often during the menstrual cycle [4]. Secondary dysmenorrhea has pathological findings such as pelvic inflammatory disease, fibroids, polycystic ovary syndrome, and endometriosis [5].

Received: 1 November, 2020 Revised: 7 December, 2020 Accepted: 8 December, 2020

Corresponding author: Seungwon Lee (ORCID https://orcid.org/0000-0002-0413-0510)

Department of Physical Therapy, College of Health Science and Social Welfare, Sahmyook University, 815 Hwarang-ro, Nowon-gu, Seoul 01795 , Republic of Korea Tel: 82-2-3399-1630 Fax: 82-2-3399-1639 E-mail: swlee@syu.ac.kr

(c) This is an Open-Access article distributed under the terms of the Creative Commons Attribution Non-Commercial License (http://creativecommons.org/licenses/ by-nc/4.0) which permits unrestricted non-commercial use, distribution, and reproduction in any medium, provided the original work is properly cited.

Copyright @ 2020 Korean Academy of Physical Therapy Rehabilitation Science 
Prostagladin is considered the physiological cause of dysmenorrhea. Secreted from endometrial cells during the menstrual period, prostaglandin causes ischemia and contraction of the uterine muscles [2]. However, the physiopathology of dysmenorrhea is still under discussion and is not completely clear [6].

Another cause of dysmenorrhea is a disorder of the autonomic nervous system accompanied by inhibition of the vagus nerve function and enhancement of sympathetic activity [7]. Previous studies compared women with dysmenorrhea and healthy women, and the result showed different autonomic reactions [8]. Compared to healthy women, sympathetic activity increased significantly and parasympathetic activity decreased in women with premenstrual syndrome $[9,10]$.

In obstetrics and gynecology, it is reported that the treatment of menstrual disorders related to dysmenorrhea is effective through autonomic nervous system regulation $[11,12]$. The autonomic nerve maintains the homeostasis of the internal environment of the human body through the interaction between the sympathetic nerve and the parasympathetic nerve according to the change of the external environment. Therefore, the disharmony between the 2 systems may cause various symptoms [9]. Previous studies reported that the sympathetic activity of women with menstrual disorder was significantly increased and that the parasympathetic activity was significantly decreased during the late luteal phase $[9,10,13]$, while another study reported that healthy women had greater parasympathetic activity in the early to intermediate follicular stages of the menstrual cycle than in the luteal phase [14]. This is considering sympathetic hyperactivity, and it is believed that the more severe the dysmenorrhea is, the more the autonomic imbalance will be [7].

Heart rate variability (HRV) analysis is a non-invasive method that can easily apply autonomic function assessment [15]. Previous studies also used this analysis method to confirm the association between dysmenorrhea and the autonomic nerve system $[7,16,17]$. HRV refers to the change in the interval between the heart rate and rate (RR interval) [18]. When the autonomic nervous system function is abnormal or weak, the change in HRV does not appear to be significant. Conversely, when the autonomic nervous system functions well, a severe change in HRV appears, which means adapting to various changes [15].

Nonsteroidal anti-inflammatory drugs (NSAIDs) and hormonal contraceptives are available to relieve menstrual pain and relax the uterine muscles [2]. However, alternative treatment methods have been studied due to the $20 \%-25 \%$ failure rate of drug treatment and a wide range of side effects [19]. Among the many alternative treatment methods for treating primary dysmenorrhea, physical therapy and manual therapy show the highest proportion of physician referral [20]. Recently, the number of patients seeking manual therapy as an approach to pain has been increasing [21].

Previous studies reported that abnormal spine arrangement is a decisive cause of not only spinal diseases, but also degenerative changes such as changes in blood vessels, decline in organ function, headache, and chronic fatigue, as well as abnormalities in the autonomic nervous system [22]. In particular, the 10th spine to the 1st lumbar bone and the 2 nd to 4 th sacrum segments are closely related to the sympathetic and parasympathetic nerves [23].

Among them, the sacrum and the uterus are neurologically connected to the pelvic splanchinic nerves (parasympathetic) starting from the 2 nd to the 5 th sacrum and mechanically connected to the uterosacral ligament [24-26]. In addition, the anterior and posterior inclinations of the sacrum may affect not only the 5 th lumbar bone and the 1 st sacrum, but also the higher vertebral segments [27].

According to previous studies, the ligaments that connect the sacrum and the surrounding frame or the sacrum nerve roots passing around them have a close relationship with the uterus [28]. Therefore, excessive uterine contraction during the menstrual period affects blood circulation by compressing the surrounding soft tissues and blood vessels, leading to the judgment that it is related to pain in the pelvis as well as pain in the sacrum [28]. Another study reported that manual therapy was applied to the sacrum and as a result, dysmenorrhea could be relieved by reducing the tension in the ligaments around the uterus or pelvic nerve roots [5].

Several studies have evaluated the effectiveness of manual therapy in women with primary menstrual pain. As a result, manual therapy affected pain perception, dysmenorrhea, and plasma levels of some chemical mediators [5,29-31].

Based on these results, manual therapy that affects the location of the sacrum may be highly related to dysmenorrhea. In the previous studies to date, however, there have been only a few studies that performed manual therapy on a specific spinal joint, and an evaluation method involving a large number of subjective factors of the patient has been used.

Therefore, this study was conducted to present a more effective treatment method by applying manual therapy to the sacroiliac joint in women with primary dysmenorrhea and confirming changes in the autonomic nervous system 
through the HRV analysis.

\section{Methods}

\section{Participants}

We recruited women aged 18 and 50 with primary dysmenorrhea symptoms for at least 1 year through flyer advertisement from September 14, 2020 to September 29, 2020 at The Wells Clinic, Minimal Pilates, in Seoul, Easy Rehabilitation Medicine Clinic in Suwon.

The selection criteria for this study were those who have a menstrual cycle (24 to 32 days), those with dysmenorrhea -related back pain symptoms above $50 \mathrm{~mm}$ on the Visual Analogue Scale (VAS), and those with a body mass index between $20 \mathrm{~kg} / \mathrm{m}^{2}$ and $30 \mathrm{~kg} / \mathrm{m}^{2}$ [32]. The exclusion criteria included those with gynecological findings such as pelvic inflammatory disease, fibroids, polycystic ovary syndrome, endometriosis, etc., those who used intrauterine contraceptive devices, those who took contraceptives or NSAIDs at the time of the experiment, those who received manipulation within 1 month of the experiment, those who were contraindicated to manipulation, and those who were scared or stressed by manipulation [33].

A total of 37 subjects were recruited, and the final 33 were selected through the selection and exclusion criteria. After that, they were randomly assigned to either the manual therapy group $(n=17)$ or the sham treatment group $(n=16)$ through the Microsoft Excel 2016 (Microsoft, Redmond, WA, USA). In the sham treatment group, however, a total of 3 patients were eliminated due to fear of manipulation $(n=3)$ and due to feeling burdensome of the treatment postures caused by menstrual blood leakage $(n=1)$ (Figure 1). This study was conducted according to the approval of the Institutional Review Board of Sahmyook University (IRB No. 2-1040781-A-N-012020101HR).

All participants were given detailed explanations on the purpose and necessary matters of the study, and voluntarily signed the relevant consent form. In addition, an experienced physical therapist explained to the subjects that they could stop whenever they wanted even during the study.

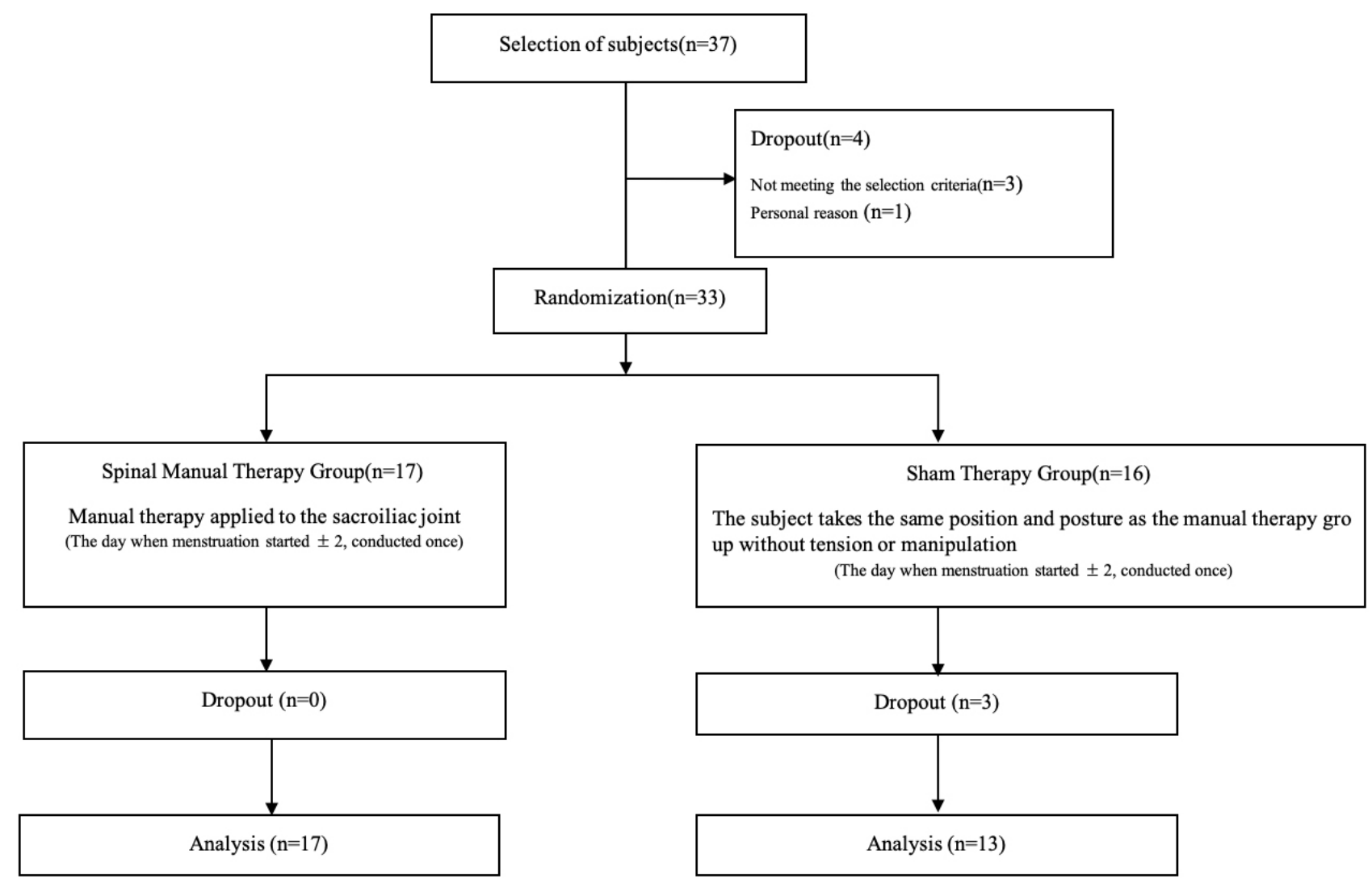

Figure 1. Flow chart. 


\section{Experimental methods}

\section{Intervention in the manual therapy group}

The manual therapy method applied to the sacroiliac joint used high-velocity, low amplitude (HVLA) manipulation. Applying force to the treatment is typically performed in less than 200 milliseconds [34]. To manipulate the sacroiliac joint, the subject laid on her side. The mediator bent the upper knee and pelvis to flex the lumbar bone. Then, the pisiform bone in the mediator's hand was contacted between the sacroiliac joint and the posterior superior iliac spine (PSIS), and the manipulation is performed.

After this, the pisiform bone in the mediator's hand was in contact between the sacroiliac joint and the PSIS, and a line of drive manipulation was performed in the anterosuperior and medial to lateral direction. Manipulation was performed to both sides of the sacroiliac joint [35].

Previous studies used audible release as an indirect indication that the manipulation was performed at a sufficient manipulation rate to elicit a reflex response in the surrounding muscles [36]. Therefore, if the movement of the sacroiliac joint was not enough or there was no audible release after the mediator's 1st manipulation, the manipulation was performed once more. Up to 2 manipulations were applied to each subject (Figure 2).

\section{Intervention in the sham treatment group}

The subjects are asked to assume the same position and posture as previously described and then to hold it for $30 \mathrm{sec}-$ onds (time taken for the manipulation of one sacroiliac joint). The mediator did not apply tension or manipulate it.

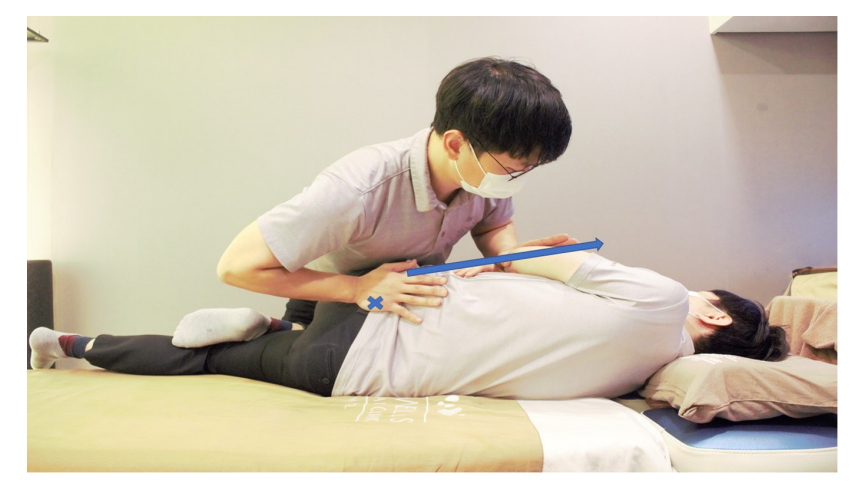

Figure 2. Manual therapy. Blue arrows indicate the line of drive. Blue $\mathrm{X}$ indicate the contact point (posterior superior iliac spine).

\section{Measure}

Based on the fact that the subjects generally complained of a lot of pain on the 1st day of menstruation [37], the evaluation period was set to the day of menstruation \pm 2 in the previous studies.

\section{Heart rate variability}

In order to prevent the autonomic nervous system from being affected by the external environment when measuring $\mathrm{HRV}$, the measurement was conducted in a room maintained at a constant temperature between $20^{\circ} \mathrm{C}$ and $25^{\circ} \mathrm{C}$. In addition, excessive exercise, smoking and drinking were prohibited within 12 hours of measurement.

As a measuring device, an autonomic nerve balance tester (SA-3000new; MEDICORE Co., Seongnam, Korea) was used. While the subject was lying with her eyes open, electrodes were placed in 3 areas (left arm, left leg, and right leg) and carried out for 3 minutes. After the intervention, the subject was re-measured after taking a break for 5 minutes (Figure 3).

HRV is evaluated by 2 methods: time domain analysis and frequency domain analysis [38]. As the time domain analysis, the standard deviation of all normal R-R intervals (SDNN) is the root mean square of successive normal to normal interval difference (RMSSD) was the square root of the



Figure 3. Autonomic nervous system electrode placement. 
mean of the sum of the square of differences between adjacent N-N intervals. It is used to evaluate the parasympathetic regulation of the heart in the time domain analysis.

In the frequency domain, TP (total power) is the sum of the intensity of very low frequency, low frequency (LF), and high frequency (HF), representing overall autonomic activity, and LF reflects the function of the sympathetic nerve and HF reflects the function of the parasympathetic nerve.

$\mathrm{LF} / \mathrm{HF}$ refers to the relative balance and ratio of the sympathetic and parasympathetic nervous systems [15,39]. In addition, items automatically recorded in the analyzer after data processing based on the measured value of HRV include autonomic activity and autonomic balance [40].

In this study, SDNN, RMSSD, TP, LF, and HF were measured. However, since TP, LF, and HF showed an ex-

Table 1. General characteristics of patients

$(\mathrm{N}=30)$

\begin{tabular}{|c|c|c|c|}
\hline \multirow{2}{*}{ Parameters } & Manual treatment & Sham therapy & \multirow{2}{*}{$\mathrm{t}(p)$} \\
\hline & $(\mathrm{n}=17)$ & $(n=13)$ & \\
\hline Age (y) & $30.24(5.57)$ & $28.54(4.48)$ & $0.92(0.36)$ \\
\hline Height $(\mathrm{cm})$ & $164.78(5.59)$ & $164.38(3.50)$ & $0.24(0.81)$ \\
\hline Weight (kg) & $57.29(4.13)$ & $56.23(3.14)$ & $0.80(0.47)$ \\
\hline $\operatorname{BMI}\left(\mathrm{kg} / \mathrm{m}^{2}\right)$ & $21.08(0.87)$ & $20.81(1.17)$ & $0.69(0.47)$ \\
\hline
\end{tabular}

Values are presented as mean (SD).

BMI: body mass index. ponential increase in actual analysis, logarithmic values of ln TP, ln LF, and ln HF were used [38].

A physical therapist who did not receive information about the group performed the HRV assessment.

\section{Pain}

The VAS was used to measure the level of pain in the lower back. At both ends on the $100 \mathrm{~mm}$ line, 0 indicated 'no pain', 10 indicated 'very painful', and the subject was asked to mark the question "What is the intensity of the pain you are currently experiencing?".

\section{Simple size}

Based on previous studies that applied pelvic manipulation to female with primary dysmenorrhea, an effect size of 0.57 was obtained through the change values in the VAS before and after intervention [33]. Therefore, the authors set the effect size, the power and the significance level to 0.57 , 0.80 and 0.05 , respectively and performed the calculation with $\mathrm{G}^{*}$ power 3.1.9.6 (Franz Faul, Universität Kiel, Kiel, Germany) program, requiring a total of 28 subjects. However, it was not easy to match the exact menstrual cycle, and a total of 37 subjects were recruited in consideration of the $30 \%$ dropout rate.

\section{Statistical analysis}

IBM SPSS Statistics for Windows, Ver. 22.0 (IBM Co.,

Table 2. Comparison of HRV and VAS between groups

\begin{tabular}{|c|c|c|c|c|c|c|c|c|}
\hline \multirow{2}{*}{ Parameters } & \multicolumn{3}{|c|}{ Manual treatment $(n=17)$} & \multicolumn{3}{|c|}{ Sham therapy $(n=13)$} & \multirow{2}{*}{$F$} & \multirow{2}{*}{ CI } \\
\hline & Pre & Post & Change & Pre & Post & Change & & \\
\hline SDNN (ms) & $44.52(15.12)$ & $43.04(17.58)$ & $-1.48(12.04)$ & $44.41(10.79)$ & $44.51(12.53)$ & $0.09(11.35)$ & 0.005 & $-5.12-3.74$ \\
\hline $\begin{array}{l}\text { RMSDD } \\
(\mathrm{ms})\end{array}$ & $43.94(18.62)$ & $42.44(18.11)$ & $-1.49(6.41)$ & $40.93(14.21)$ & $41.83(16.44)$ & $0.89(7.57)$ & 0.224 & $-2.91-2.31$ \\
\hline $\mathrm{TP}\left(\log \mathrm{ms}^{2}\right)$ & $7.13(0.73)$ & $7.14(0.76)$ & $0.00(0.48)$ & $6.85(0.85)$ & $6.52(0.81)$ & $-0.32(0.77)$ & 1.968 & $-0.37-0.12$ \\
\hline $\mathrm{LF}\left(\log \mathrm{ms}^{2}\right)$ & $5.81(1.20)$ & $5.82(0.85)$ & $0.24(0.72)$ & $5.76(0.66)$ & $5.17(0.91)$ & $-0.65(0.92)^{*}$ & $<0.001$ & $-0.47-0.137$ \\
\hline $\mathrm{HF}\left(\log \mathrm{ms}^{2}\right)$ & $6.01(0.86)$ & $5.91(0.87)$ & $-0.09(0.38)$ & $6.03(0.92)$ & $6.05(1.06)$ & $0.01(0.41)$ & 0.096 & $-0.18-0.11$ \\
\hline $\begin{array}{l}\text { ANS } \\
\text { activity } \\
\text { (score) }\end{array}$ & $105.88(19.30)$ & $106.57(18.66)$ & $0.69(12.01)$ & $99.93(16.39)$ & $101.15(14.36)$ & $1.22(14.25)$ & 1.446 & $-3.97-5.89$ \\
\hline $\begin{array}{c}\text { Balance } \\
\text { of ANS } \\
\text { (score) }\end{array}$ & $106.38(32.83)$ & $75.18(46.68)$ & $-31.20(34.96)^{*}$ & $79.73(46.71)$ & $124.68(10.84)$ & $44.94(46.98)^{*}$ & $4.631^{*}$ & $-8.43-22.17$ \\
\hline VAS (mm) & $72.35(18.55)$ & $52.94(23.65)$ & $-19.41(18.19)^{*}$ & $60.77(11.15)$ & $51.54(11.43)$ & $-9.23(11.15)^{*}$ & 0.990 & $8.44-20.19$ \\
\hline
\end{tabular}

Values are presented as mean (SD).

SDNN: the standard deviation of all normal R-R intervals, RMSSD: the root mean square of successive normal to normal interval difference, TP: total power, LF: low frequency, HF: high frequency, ANS: autonomic nervous system, VAS: visual analogue scale, CI: confidence intervals. *Significant difference between pre-test and post-test $(p<0.05)$. 
Armonk, NY, USA) was used for data analysis and statistical processing. All subjects were tested for KolmogorovSmirnov normality, and descriptive statistics were used for general characteristics of subjects. The comparison before and after treatment was performed by a paired sample t-test, and repeated measurement analysis of variance was used to find out the differences between groups. The significance level was set to 0.05 .

\section{Results}

The general characteristics of the manual therapy group and the sham therapy group were found to be identical in both groups. The general characteristics of the subjects were as follows (Table 1).

\section{Changes in heart rate variability according to treatment}

In manual therapy, the autonomic balance of HRV decreased significantly by $29.32 \%$ from 106.38 to 75.18 $(p<0.05)$. In the sham therapy group, LF significantly decreased by $10.24 \%$ from $5.76 \log \mathrm{ms}^{2}$ to $5.17 \log \mathrm{ms}^{2}$, while significantly increasing by $55.65 \%$ from 79.73 to 124.68 in the autonomic renal balance $(p<0.05)$. In the difference between the 2 groups according to treatment, there was a significant difference only for autonomic balance $(p<0.05)$ (Table 2).

\section{Changes in the visual analogue scale according to treat- ment}

The VAS decreased significantly by $26.93 \%$ from 72.35 $\mathrm{mm}$ to $52.94 \mathrm{~mm}$ in manual therapy $(p<0.05)$, while it decreased by $15.29 \%$ from $60.77 \mathrm{~mm}$ to $51.54 \mathrm{~mm}$ in the sham therapy group $(p<0.05)$. There was no significant difference between the 2 groups according to treatment $(p>0.05)$ (Table 2).

\section{Discussion}

In this study, manual therapy was applied to the sacroiliac joint in patients with primary dysmenorrhea to confirm for changes in back pain and HRV.

As a result, autonomic balance significantly decreased by $29.32 \%$ from 106.38 score to 75.18 score in the manual therapy group $(p<0.05)$. In the sham therapy group, LF significantly decreased by $10.24 \%$ from $5.76 \mathrm{~ms}^{2}$ to $5.17 \mathrm{~ms}^{2}$ $(p<0.05)$, and autonomic balance increased significantly by $55.65 \%$ from a score of 79.73 to $124.68(p<0.05)$. There was a significant difference in autonomic balance between the 2 groups $(p<0.05)$.

When the ratio of the sympathetic and parasympathetic nervous system is $6: 4$, it is reported that the balance of the autonomic nervous system is stable [15,39]. When recalculated, it may be considered as 1:0.6. In addition, autonomic balance of less than 50 is the normal category [39], and the lower it is, the more it is included in the normal category.

Before treatment, the ratio of the sympathetic nervous system to the parasympathetic nervous system was calculated as 1:1.03 before treatment in the manual therapy group applied in this study, while it was 1:1.04 in the sham treatment group. In order to be included in the normal category, LF must be increased or HF must be decreased. In the manual therapy group, HF decreased from 6.01 to 5.91 and changed to $1: 1.01$, a ratio slightly closer to the normal category, while in the sham treatment group, LF decreased from 5.76 to 5.17 , changing to $1: 1.17$, which is a ratio away from the normal category. Therefore, it is judged that the manual therapy group is more effective in achieving autonomic balance than the sham therapy group.

Previous studies confirming the association between the spine and the autonomic nervous system found out whether it affected blood pressure, heart rate, and renal sympathetic activity through mechanical stimulation of the spine, and showed afferent activation of the spine [41]. Another study reported that when a harmful chemical stimulus was applied to the interspinous tissues in rats, the blood pressure of the whole body was greatly increased and blood flow of the sciatic nerve increased [42]. A similar study reported that when a harmful chemical stimulus was applied to the spinal tissues of the spine and lumbar bones, the adrenal sympathetic nerve and catecholamine secretion increased [43].

It also reported that sympathetic activity increased significantly and parasympathetic activity decreased significantly in women with menstrual disorders during the late luteal phase $[9,10,13]$. Another study found out that healthy women had greater parasympathetic nerves during the early to intermediate follicular stages of the menstrual cycle compared to the luteal phase [14]. This is considered to be sympathetic hyperactivity, and it is believed that the more severe dysmenorrhea, the more the autonomic imbalance [7].

Based on these facts, it is judged that the spine and primary dysmenorrhea are closely related. In particular, dysfunction shown in the sacroiliac joint [44], which may affect the function of all spinal joints, can lead to disorders in autonomic nervous system balance, biomechanical movement 
and circulation capacity [45]. In addition, the free movement of the sacrum may have an effect on maintaining the balance of the autonomic nerve by the activity of the parasympathetic nerve of the 2nd to 4th sacral ventral rami (S2-4 ventral rami) [46].

Therefore, it is believed that the manual therapy of sacroiliac joints used in this study may have affected the upper spine along with the change in the location of the sacrum and the autonomic nerve [47]. As a result, it is judged that it was linked to the activity of the parasympathetic nerve and had a significant effect on the autonomic balance.

The VAS for back pain significantly decreased by $26.93 \%$ from $72.35 \mathrm{~mm}$ to $52.94 \mathrm{~mm}$ in the sacroiliac joint manual therapy group, while $15.29 \%$ from $60.77 \mathrm{~mm}$ to $51.54 \mathrm{~mm}$ in the sham treatment group $(p<0.05)$. There was no significant difference between the 2 groups ( $p>0.05$ ).

For subjects with back pain, the minimum detectable change (MDC) on the VAS after treatment should have a difference of $18-19 \mathrm{~mm}$ for the mean value of $64 \mathrm{~mm}$ [48]. The MDC was identified for the subjects participating in the experiment. As a result, it was found in $76.47 \%$ of the subjects in the manual therapy group, while only $30.76 \%$ of the subjects showed a difference in the sham treatment group. It can be seen that manual therapy is more effective in relieving back pain than sham therapy.

The HVLA used in this study is believed to be able to temporarily change the cortical plasticity while significantly reducing the excitability of the cortical spinal cord and spinal cord reflexes [49]. In addition, the release of $\beta$ endorphins [50] and the opioid effect on the peripheral nervous system were also judged to be related to pain relief [51].

Therefore, pain relief in the manual therapy group is thought to be neurophysiological responses to the central and peripheral nervous systems [52] and the effects on chemical mediators at the plasma level associated with pain, including prostaglandins $[31,53,54]$, and finally, the effects of autonomic balance.

Based on these results, it is believed that manual therapy of the sacroiliac joint would be an appropriate alternative treatment method for female with primary dysmenorrhea.

The limitations of this study are as follows: The autonomic nervous system is highly related to age, but the age of the subjects who participated in the experiment varied from 18 to 50 years old. Also, the degree to which the effect of the manual therapy was maintained was not confirmed. Finally, the number of test subjects was too insufficient to generalize. In order to compensate for these limitations, ad- ditional studies that prove various effects after applying manual therapy for a long time and a large number of subjects of the same age are considered to be necessary.

As a result, manual therapy applied to the sacroiliac joints of female with primary dysmenorrhea reduced the change in autonomic balance and lower back pain of HRV in a short time. This may indicate that manual therapy is effective for primary dysmenorrhea, and if a longer-term interventional protocol is applied, it will help to overcome chronic primary dysmenorrhea.

\section{Conflict of Interest}

The authors declared no potential conflicts of interest with respect to the authorship and/or publication of this article.

\section{References}

1. Eccles NK. A randomized, double-blinded, placebo-controlled pilot study to investigate the effectiveness of a static magnet to relieve dysmenorrhea. J Altern Complement Med 2005;11:681-7.

2. Proctor M, Farquhar C. Diagnosis and management of dysmenorrhoea. BMJ 2006;332:1134-8.

3. Polat A, Celik H, Gurates B, Kaya D, Nalbant M, Kavak E, et al. Prevalence of primary dysmenorrhea in young adult female university students. Arch Gynecol Obstet 2009;279:527-32.

4. Dawood MY. Primary dysmenorrhea: advances in pathogenesis and management. Obstet Gynecol 2006;108:428-41.

5. Holtzman DA, Petrocco-Napuli KL, Burke JR. Prospective case series on the effects of lumbosacral manipulation on dysmenorrhea. J Manipulative Physiol Ther 2008;31:237-46.

6. Proctor ML, Hing W, Johnson TC, Murphy PA. Spinal manipulation for primary and secondary dysmenorrhoea. Cochrane Database Syst Rev 2001;(4):CD002119.

7. Lee JM, Lee CH, Cho JH, Jang JB, Lee KS, Lee JY. Analysis on the heart rate variability of dysmenorrhoea patients. J Orient Obstet Gynecol 2007;20:164-77.

8. Park MK, Watanuki S. Specific physiological responses in women with severe primary dysmenorrhea during the menstrual cycle. J Physiol Anthropol Appl Human Sci 2005;24:601-9.

9. Matsumoto T, Ushiroyama T, Morimura M, Moritani T, Hayashi $\mathrm{T}$, Suzuki T, et al. Autonomic nervous system activity in the late luteal phase of eumenorrheic women with premenstrual symptomatology. J Psychosom Obstet Gynaecol 2006;27:131-9.

10. Baker FC, Colrain IM, Trinder J. Reduced parasympathetic activity during sleep in the symptomatic phase of severe premenstrual syndrome. J Psychosom Res 2008;65:13-22.

11. Cho SH, Hwang EW. Acupuncture for primary dysmenorrhoea: a systematic review. BJOG 2010;117:509-21.

12. Lee S, Lee MS, Choi JY, Lee SW, Jeong SY, Ernst E. Acupuncture and heart rate variability: a systematic review. Auton Neurosci 2010;155:5-13.

13. Matsumoto T, Ushiroyama T, Kimura T, Hayashi T, Moritani T. Altered autonomic nervous system activity as a potential etio- 
logical factor of premenstrual syndrome and premenstrual dysphoric disorder. Biopsychosoc Med 2007;1:24.

14. McKinley PS, King AR, Shapiro PA, Slavov I, Fang Y, Chen IS, et al. The impact of menstrual cycle phase on cardiac autonomic regulation. Psychophysiology 2009;46:904-11.

15. Pumprla J, Howorka K, Groves D, Chester M, Nolan J. Functional assessment of heart rate variability: physiological basis and practical applications. Int J Cardiol 2002;84:1-14.

16. Leicht AS, Hirning DA, Allen GD. Heart rate variability and endogenous sex hormones during the menstrual cycle in young women. Exp Physiol 2003;88:441-6.

17. Vagedes J, Fazeli A, Boening A, Helmert E, Berger B, Martin D. Efficacy of rhythmical massage in comparison to heart rate variability biofeedback in patients with dysmenorrhea-a randomized, controlled trial. Complement Ther Med 2019;42:438-44.

18. Tarvainen MP, Niskanen JP. Kubios HRV 2.1 user's guide. Kuopio: University of Eastern Finland; 2012.

19. $\mathrm{Yu} \mathrm{A}$. Complementary and alternative treatments for primary dysmenorrhea in adolescents. Nurse Pract 2014;39:1-12.

20. Astin JA, Marie A, Pelletier KR, Hansen E, Haskell WL. A review of the incorporation of complementary and alternative medicine by mainstream physicians. Arch Intern Med 1998;158:2303-10.

21. Christensen MG, Kollasch MW, Ward R, Webb KR, Day AA, zumBrunnen J. Job analysis of chiropractic 2005: a project report, survey analysis, and summary of the practice of chiropractic within the United States. Greeley (CO): National Board of Chiropractic Examiners; 2005.

22. Liebenson C. Rehabilitation of the spine: a practitioner's manual. 2nd ed. Philadelphia (PA): Lippincott Williams \& Wilkins; 2007.

23. Latthe PM, Proctor ML, Farquhar CM, Johnson N, Khan KS. Surgical interruption of pelvic nerve pathways in dysmenorrhea: a systematic review of effectiveness. Acta Obstet Gynecol Scand 2007;86:4-15.

24. Mauroy B, Demondion X, Bizet B, Claret A, Mestdagh P, Hurt C. The female inferior hypogastric (= pelvic) plexus: anatomical and radiological description of the plexus and its afferences--applications to pelvic surgery. Surg Radiol Anat 2007;29:55-66.

25. Proctor ML, Hing W, Johnson TC, Murphy PA. Spinal manipulation for primary and secondary dysmenorrhoea. Cochrane Database Syst Rev 2006;2006:CD002119.

26. Buller JL, Thompson JR, Cundiff GW, Krueger Sullivan L, Schön Ybarra MA, Bent AE. Uterosacral ligament: description of anatomic relationships to optimize surgical safety. Obstet Gynecol 2001;97:873-9.

27. Vleeming A, Stoeckart R. The role of the pelvic girdle in coupling the spine and the legs: a clinical-anatomical perspective on pelvic stability. In: Vleeming A, Mooney V, Stoeckart R, editors. Movement, stability \& lumbopelvic pain: integration of research and therapy. 2nd ed. Edinburgh: Churchill Livingstone Elsevier; 2007. p. 113-37.

28. Browning JE. Pelvic pain and organic dysfunction in a patient with low back pain: response to distractive manipulation: a case presentation. J Manipulative Physiol Ther 1987;10:116-21.

29. Boesler D, Warner M, Alpers A, Finnerty EP, Kilmore MA. Efficacy of high-velocity low-amplitude manipulative technique in subjects with low-back pain during menstrual cramping. J Am Osteopath Assoc 1993;93:203-8, 213-4.

30. Hondras MA, Long CR, Brennan PC. Spinal manipulative ther- apy versus a low force mimic maneuver for women with primary dysmenorrhea: a randomized, observer-blinded, clinical trial. Pain 1999;81:105-14.

31. Kokjohn K, Schmid DM, Triano JJ, Brennan PC. The effect of spinal manipulation on pain and prostaglandin levels in women with primary dysmenorrhea. J Manipulative Physiol Ther 1992; 15:279-85.

32. Zecchillo D, Acquati A, Aquino A, Pisa V, Uberti S, Ratti S. Osteopathic manipulative treatment of primary dysmenorrhea and related factors: a randomized controlled trial. Int J Med Res Health Sci 2017;6:165-74.

33. Molins-Cubero S, Rodríguez-Blanco C, Oliva-Pascual-Vaca Á, Heredia-Rizo AM, Boscá-Gandía JJ, Ricard F. Changes in pain perception after pelvis manipulation in women with primary dysmenorrhea: a randomized controlled trial. Pain Med 2014;15: 1455-63.

34. Herzog W. Mechanical, physiologic, and neuromuscular considerations of chiropractic treatments. Adv Chiropr 1996;3:69-285.

35. Jones $\mathrm{K}$. The effect of sacroiliac joint manipulation on lumbar extensor muscle endurance in asymptomatic individuals [Master thesis]. Durban: Durban University of Technology; 2014.

36. Flynn TW, Fritz JM, Wainner RS, Whitman JM. The audible pop is not necessary for successful spinal high-velocity thrust manipulation in individuals with low back pain. Arch Phys Med Rehabil 2003;84:1057-60.

37. Harlow SD, Park M. A longitudinal study of risk factors for the occurrence, duration and severity of menstrual cramps in a cohort of college women. Br J Obstet Gynaecol 1996;103:1134-42.

38. Kaya H, Süner A, Köroğlu S, Akçay A, Türkbeyler İH, Köleoğlu M. Heart rate variability in familial Mediterranean fever patients. Eur J Rheumatol 2014;1:58-61.

39. Heart rate variability: standards of measurement, physiological interpretation and clinical use. Task Force of the European Society of Cardiology and the North American Society of Pacing and Electrophysiology. Circulation 1996;93:1043-65.

40. Shin S, Kim K, Ko H. Fatigue diagnostic measure research through the heart rate variability of chronic fatigue patients and healthy students in Korean medical hospital. J Physiol Pathol Korean Med 2015;29:409-15.

41. Akselrod S, Gordon D, Ubel FA, Shannon DC, Berger AC, Cohen RJ. Power spectrum analysis of heart rate fluctuation: a quantitative probe of beat-to-beat cardiovascular control. Science 1981;213:220-2.

42. Budgell B. Spinovisceral reflexes evoked by noxious and innocuous stimulation of the lumbar spine. J Neuromusculoskelet Syst 1995;3:122-31.

43. Budgell B, Sato A, Suzuki A, Uchida S. Responses of adrenal function to stimulation of lumbar and thoracic interspinous tissues in the rat. Neurosci Res 1997;28:33-40.

44. DonTigny RL. Anterior dysfunction of the sacroiliac joint as a major factor in the etiology of idiopathic low back pain syndrome. Phys Ther 1990;70:250-65; discussion 262-5.

45. Glover J, Talsma J, Pierce-Talsma S. An osteopathic approach to diagnosis and management of sacroiliac joint dysfunction. J Am Osteopath Assoc 2018;118:e92-3.

46. Heinking KP, Kappler RE. Pelvis and sacrum. In: Chila AG, editor. Foundations of osteopathic medicine. 3rd ed. Philadelphia (PA): Lippincott Williams \& Wilkins; 2011. p. 575-601. 
47. Hitchcock ME. The manipulative approach to the management of primary dysmenorrhea. J Am Osteopath Assoc 1976;75:909-18.

48. Hägg $\mathrm{O}$, Fritzell $\mathrm{P}$, Nordwall A. The clinical importance of changes in outcome scores after treatment for chronic low back pain. Eur Spine J 2003;12:12-20.

49. Fryer G, Pearce AJ. The effect of lumbosacral manipulation on corticospinal and spinal reflex excitability on asymptomatic participants. J Manipulative Physiol Ther 2012;35:86-93.

50. Walsh MJ, Polus BI. A randomized, placebo-controlled clinical trial on the efficacy of chiropractic therapy on premenstrual syndrome. J Manipulative Physiol Ther 1999;22:582-5.

51. Grayson JE, Barton T, Cabot PJ, Souvlis T. Spinal manual therapy produces rapid onset analgesia in a rodent model. Man Ther
2012;17:292-7.

52. Bialosky JE, Bishop MD, Price DD, Robinson ME, George SZ. The mechanisms of manual therapy in the treatment of musculoskeletal pain: a comprehensive model. Man Ther 2009;14:531-8.

53. Degenhardt BF, Darmani NA, Johnson JC, Towns LC, Rhodes DC, Trinh C, et al. Role of osteopathic manipulative treatment in altering pain biomarkers: a pilot study. J Am Osteopath Assoc 2007;107:387-400.

54. Skyba DA, Radhakrishnan R, Rohlwing JJ, Wright A, Sluka KA. Joint manipulation reduces hyperalgesia by activation of monoamine receptors but not opioid or GABA receptors in the spinal cord. Pain 2003;106:159-68. 